\title{
Correction to: Differences in perceived intra-oral dryness in various dry-mouth patients as determined using the Regional Oral Dryness Inventory
}

\author{
Z. Assy $^{1} \cdot$ C. P. Bots ${ }^{2} \cdot$ H. Z. Arisoy ${ }^{1} \cdot$ S. S. Gülveren ${ }^{1} \cdot$ F. J. Bikker ${ }^{1} \cdot$ H. S. Brand ${ }^{1}$
}

Published online: 30 September 2021

๑) Springer-Verlag GmbH Germany, part of Springer Nature 2021

\section{Correction to: Clinical Oral Investigations}

https://doi.org/10.1007/s00784-020-03734-2

During rereading of the article, we discovered that some numbers are missing in Table 4 . The number of medications for SS patients in Table 4 should be ' $2 \pm 1-2$ ', and not ' $\pm 1-2$ '.

The original article has been corrected.

Publisher's note Springer Nature remains neutral with regard to jurisdictional claims in published maps and institutional affiliations.

The original article can be found online at https://doi.org/10.1007/ s00784-020-03734-2.

Z. Assy

z.assy@acta.nl

1 Department of Oral Biochemistry, Academic Centre for Dentistry Amsterdam, University of Amsterdam and VU University Amsterdam, Room 12N-37, Gustav Mahlerlaan 3004, 1081 LA Amsterdam, The Netherlands

2 Saliva Clinic of the Dutch Institute for Salivary Research, Bunschoten, Netherlands 